\title{
Ageing, income and living standards: evidence from the British Household Panel Survey
}

\author{
RICHARD BERTHOUD*, MORTEN BLEKESAUNE $\dagger$ \\ and RUTH HANCOCK
}

\begin{abstract}
In Britain, older people have lower average incomes and a higher risk of income poverty than the general population. Older pensioners are more likely to be in poverty than younger ones. Yet certain indicators of their living standards suggest that older people experience less hardship than expected, given their incomes. A possible explanation is that older people convert income into basic living standards at a higher rate than younger people, implying that as people age they need less income to achieve a given standard of living. Much existing evidence has been based on cross-sectional data and therefore may not be a good guide to the consequences of ageing. We use longitudinal data on people aged at least $5^{0}$ years from the British Household Panel Survey to investigate the effects of ageing on the relationship between standard of living, as measured by various deprivation indices, and income. We find that for most indices, ageing increases deprivation when controlling for income and other factors. The exception is a subjective index of 'financial strain', which appears to fall as people age. We also find evidence of cohort effects. At any given age and income, more-recently-born older people in general experience more deprivation than those born longer ago. To some extent these ageing and cohort effects balance out, which suggests that pensions do not need to change with age.
\end{abstract}

KEY WORDS - ageing, older people, cohort, living standards, deprivation, income.

\section{Introduction}

In Britain, in comparison with the general population, older people have lower average incomes, and most sources and estimates suggest that they have a higher risk of income poverty. In 2006/7 i 8 per cent of all individuals had a net household income (before housing costs) of below

* Institute for Social and Economic Research, University of Essex, Colchester, UK.

$\dagger$ Norwegian Social Research (NOVA), Oslo, Norway.

+ Health Economics Group, Faculty of Health, University of East Anglia, Norwich, UK. 
60 per cent of the median, but among pensioners the proportion was 23 per cent (Department for Work and Pensions 2008). In the pensioner population, older pensioners were more likely to be in poverty than younger ones. Yet certain indicators of their living standards suggest that older people experience less hardship than might be expected, given their income. A recent study found that one-quarter of low-income pensioner households spent no more than two-thirds of their income (Finch and Kemp 2006). This is inconsistent with a simple prediction from the lifecycle model of consumption, that in retirement people would spend more than their incomes by drawing on their savings. Explanations for this socalled 'retirement-savings' or 'retirement-consumption' puzzle include unanticipated shocks, precautionary savings, a desire to pass on wealth to the next generation, and the substitution of leisure for consumption (Banks, Blundell and Tanner I998; Miniaci, Monfordini and Weber 2003; Smith 2006).

Data from the British Poverty and Social Exclusion Survey (PSE) indicate that pensioners have high rates of income-poverty (Gordon et al. 2000; Patsios 2000; Pantazis, Gordon and Levitas 2006), but are better off on measures of lifestyle 'deprivation' than their low incomes suggest (Berthoud, Blekesaune and Hancock 2006). One explanation could be that older people convert income into basic living standards at a higher rate than younger people. If this is true and holds into late old age, the implication would be that as pensioners age, on average they need less income to achieve a given standard of living. At a time when raising pensions for older pensioners is high on the policy agenda (Pensions Policy Institute 2004), the policy conclusions of such a finding would be significant and controversial. All this suggests a pressing need for a better understanding of whether and how the relationship between the standard of living and income changes with age.

There is a considerable international literature on how incomes change during later life (for recent examples see Prus 2002; Williams and Smeeding 2004; LaRochelle-Côté, Myle and Picot 2008), but there appears to be little research on how income changes translate into changes in living standards in old age. As indicators of living standards, deprivation indices have played an important role in the analysis of poverty in Britain for several decades (Townsend I979; Berthoud and Ford I996). They have been of increasing interest across the European Union (EU) since the first EU-wide data were collected in 1994 (e.g. Atkinson et al. 2002; Guio 2005; Halleröd 1995; Whelan et al. 200I), though there has been much less interest in the United States (an exception is Mayer and Jencks I989). Relatively little attention has been paid to the surprisingly low rates of deprivation reported by older people. So far as we know, this paper is the 
first to use panel data to estimate ageing and cohort effects in the relationship between deprivation and income levels among older people.

\section{Methodological issues}

When identifying how the relationship between standards of living and income is affected by age, two important methodological issues arise. The first concerns the measurement of standard of living, and the second is whether variations in the relationship across age groups can be attributed to ageing effects or to differences between people of different generations (cohort effects). Differences across age groups observed in cross-sectional data can be interpreted as either, but depending on which is correct, the policy implications are very different.

\section{The measurement of standard of living}

The hypothesis that we wish to test is that the standard of living a household achieves from a given income depends on its members' ages, after controlling for other relevant factors, e.g. living arrangements. Since standard of living is not directly observable, we need a suitable indicator. Deprivation indices can be used as indicators of standard of living on the assumption that higher levels of (material) deprivation correspond to lower standards of living and vice versa. They have been used in previous research on variations in standards of living associated with household composition (Berthoud and Ford I996) and disability (Zaidi and Burchardt 2005). One approach to the construction of deprivation indices defines deprivation as the inability to afford common necessities. It was used in the Poverty and Social Exclusion Survey (PSE) (Gordon et al. 2000; Pantazis, Gordon and Levitas 2006) and its predecessors (Mack and Lansley i985), where the definition of necessities was established 'consensually'. As part of the PSE, respondents to the Office for National Statistics' Omnibus Survey were shown a list of 54 items and asked which 'all adults should be able to afford and which they should not have to do without'. The PSE research team chose to define 'necessities' as those items that were considered essential by at least 50 per cent of respondents. This definition has been criticised because it relies on there being general agreement about the standards of living that all people should be able to afford, and because the 50 per cent threshold is a rather weak measure of such agreement (McKay 2004).

The PSE definition of consensual deprivation ${ }^{1}$ was implemented in a follow-up of the I998-99 General Household Survey. It asked the respondents which of the listed necessities they had or did. Respondents who did not 
have the items or do the activities were asked whether this was because they did not want to do them or because they could not afford them. The distinction between not wanting and not being able to afford items is to some extent subjective. McKay's and our own re-analysis of the PSE found that pensioners were much less likely than others to say they 'can't afford' things and more likely to say they did not want them, which might indicate an unwillingness to admit that they cannot afford things (McKay 2004; Berthoud, Blekesaune and Hancock 2006). These studies also found that people who said they could not afford some 'necessities' nevertheless possessed 'non necessities'. For monitoring progress in reducing child poverty, the United Kingdom Government has adopted indicators of deprivation that make the distinction between 'not wanting' and 'not being able to afford'. It will be useful to analyse deprivation in old age with and without this distinction.

Deprivation can be absolute or relative. Absolute deprivation means that the standards are fixed in time, and relative deprivation means that the standards for being deprived change year by year. The logic of relative deprivation is that standards of living should be compared with standards enjoyed by others in the same year. Our view is that the deprivation indices we analyse are best used as indicators of relative deprivation. For example, one is based on the possession of consumer durables and therefore makes sense only in the context of the particular stage of the spread of gadgetry at which the questions were asked. Similarly, the concepts underlying indices based on aspects of daily living or feeling comfortable with one's income are inherently relative. There is now substantial empirical evidence that relative income is an important influence on subjective wellbeing (e.g. Clark, Fritjers and Shields 2008; Zigante 2008). An important technical point for our analysis is that using relative measures of deprivation avoids period effects, so that ageing and cohort effects can be identified. We are not arguing that period effects do not exist: absolute deprivation levels are very likely to vary over time, as incomes rise or as the penetration of 'essential' household equipment spreads, but we set them aside in the reported analysis in order to address other issues. We therefore use yearby-year standardised indicators of deprivation. The indices also embody both subjective and objective elements. They are based on, but are not identical to, previous analysis of the British Household Panel Survey (Berthoud, Bryan and Bardasi 2004).

\section{Ageing and cohort effects}

Differences across age groups observed at a single time point are not necessarily the result of changes which occur as people age, but may be 
attributable to cohort effects (see Portrait, Deeg and Alessi 2004). In our analysis, a cohort effect would mean that people born earlier would tend to have higher or lower levels of deprivation (for a given income) than those born later. ${ }^{2}$ In contrast an ageing effect would mean that as individuals grow older they tend to become more or less deprived (relative to the national average) than can be explained by the change in their income. The existence of cross-sectional age variations in deprivation, controlling for income, can be explained by ageing effects or cohort effects or a combination of the two. When comparing pre- and post-retirement age groups, there is also the possibility of a retirement effect: when people retire their deprivation might increase more or less than the reduction in their income. If there is a retirement effect, the variation in deprivation across age groups might be caused by progressively more people having made the transition into retirement.

At older ages, cross-sectional variations by age can also arise from differential mortality. Mortality rates are higher among the more deprived than the less deprived, as Romeri, Baker and Griffiths (2006) directly showed. We are interested here in the relationship between income and living standards, so differential mortality plays a part if longevity is related to the efficiency with which income is translated into the standard of living. If those who are less efficient at translating income into material wellbeing tend to die younger than those who are able to derive higher living standards from a given income, this would explain why, as a cohort ages and when controlling for income, its surviving members enjoy a higher living standard. But it would not mean that an individual enjoys a higher living standard from a given income as he or she ages. We have no way of estimating the likely extent of this differential.

\section{Data source, measures and analysis}

Longitudinal data and analyses have been used to disentangle the ageing, cohort and retirement effects. The data were drawn from the British Household Panel Survey (BHPS). The BHPS started in 1991 by interviewing each adult member of around 5,00o British households. They (and their children as they became adults) have subsequently been followed up each year (Taylor 2006). The reported analysis has used Waves 6 to i2 data (from approximately 1996 to 2002) since some of the main deprivation indicators were not introduced until Wave 6. The unit of analysis is the individual respondent, and the analysis has been confined to those of the original sample members who provided the information needed to construct the deprivation indices in at least five of the selected waves. 
Members of this sub-sample contributed to the data for analysis at the waves in which they were aged at least 50 years. The analysis sample has 3,726 individuals from 2,505 original households and 19,732 person-year observations. The resulting sample is in broad terms representative of older households in Great Britain. Differential attrition rates will have modified the composition of the sample over the years, but a comparison between the results when using data weighted and unweighted for attrition suggests no major impact.

\section{The dependent variables}

The dependent variables are indices of relative deprivation with higher scores representing greater deprivation or lower living standards. There are four sub-indices and an aggregate index derived from them. Each subindex was had two or more items, each of which was standardised to have a mean at zero and a standard deviation of I.o for each wave (or year). Two versions of a daily living index were constructed from one member of a household's responses, which are assumed to apply to the household as a whole. The assumption is that individual members of a household share approximately the same standard of 'daily living'. ${ }^{3}$ The questions were:

Here is a list of things which people might have or do. ${ }^{4}$ Please ... tell me which things you (and your household) have or do? Pay for a week's annual holiday away from home./Replace worn out furniture./Buy new, rather than second hand, clothes./Eat meat, chicken or fish every second day./Have friends or family for a drink or meal at least once a month. If respondents did not have the items or do the activities, they were also asked: Would you like to be able to $<$ named item or activity $>$ but must do without because you cannot afford it?

The two 'daily living' indices were compiled as follows. For the don't have index, each item scored ' $\mathrm{I}$ ' if the household did not have the item or activity, regardless of whether they could afford it, and ' $\mathrm{o}$ ' if they had/did the item/activity. The item score was then standardised by deducting the mean score and dividing by its standard deviation for the year in question. These standardised item scores were then averaged to form a single index of relative deprivation. The can't afford daily living index was constructed in the same way except that an item was scored ' $\mathrm{I}$ ' only if the households did not have/do it because it could not be afforded.

A third index was of the possession of consumer durables. The respondents were asked the question that follows, and the index was constructed by first assigning '-I' for each item the household had, with each car scoring '-I', standardising and then averaging across the items as before.

Would ... you tell me if you have any of the items listed in your (part of the) accommodation? The items were: colour TV/video cassette recorder/washing 
machine/dish washer/microwave oven/ home computer/ CD player/ telephone/ cable or satellite TV/number of cars

A financial strain index was constructed from two question blocks asked of each adult separately. The first was:

How well would you say you yourself are managing financially these days? Would you say you are/living comfortably/ doing alright/just about getting by/ finding it quite difficult/or finding it very difficult?

The answers were scored on a five-point scale from 'o' (living comfortably) to ' 4 ' (finding it very difficult). The second question block was:

Here are some questions about how you feel about your life. Please tick the number which you feel best describes how dissatisfied or satisfied you are with the following aspects of your current situation.

One item was then 'the income of your household'. The response options ranged from ' I' (not satisfied at all) to ' 7 ' (completely satisfied). For use in the deprivation index, these were inverted and scored as ' 6 ' (not satisfied at all) to 'o' (very satisfied). Each of the two components of the financial strain index was standardised and the average taken to produce the relative deprivation indicator of 'financial strain'. An overall deprivation index was computed by averaging the four (already standardised) indices and re-standardising the result (to have mean zero and standard deviation I.O).

\section{The independent variables}

The two key independent variables are age and income. Age refers to the individual's age in years. The analysis presented here assumes that the effect of each year of age is stable across the entire range: preliminary analyses had shown some minor variation in the ageing effect when using piece-wise constant age slopes (splines). For most of the analysis, income was 'total net income of the household' in which the person lived and was measured net of housing costs (mortgage payments or rent) and housing benefit (a social security benefit which helps low-income tenants with their rent). Where housing costs were included as independent variables, income was measured before they were deducted. Income was standardised to a relative measure by dividing by the ratio of the mean for the entire study period to the mean for the survey year. The regression analysis used the log of income, which earlier work had shown to have a consistent relationship with deprivation (Berthoud, Bryan and Bardasi 2004), and to predict the dependent variable more accurately than would income. Using the log of income implies that the decline in deprivation as income rises is greater at lower than higher levels of income. 
Throughout the analysis we also controlled for household composition by including whether the individual had a partner and the number of children in the household. Note that this alternative to an equivalence scale for household composition is more flexible than an externallydefined scale, and means that the effects of adults and children become an output from the analysis rather than an input. Other variables examined for possible confounding effects on the relationships between deprivation, age and income were indicators of health status, housing tenure and costs, and whether the respondent had retired from paid work. Poor health may bring extra costs, e.g. the need to take taxis rather than use public transport, or place physical constraints on activities and hence affect the standard of living achieved from a given income (Zaidi and Burchardt 2005). Housing tenure and costs are relevant because, for example, older people who are owner-occupiers are likely to have paid off their mortgages and so to have lower housing costs than people who rent in later life, which could explain differences in the achieved standard of living. There are also cohort trends in housing tenure, with more-recently-born older people more likely to have become owner-occupiers.

Four measures of health status were used: self-rated general health; limitations in activities of daily living (ADLs); sight and hearing impairments; and the presence of other specific health problems. The BHPS respondents were asked:

Please think back over the last I2 months about how your health has been. Compared to people of your own age, would you say that your health has on the whole been: excellent, good, fair, poor or very poor ?5

The five response categories were coded 'I' ('excellent') to '5' ('very poor'). An exploratory analysis indicated near linear relationships between these response codes and the two daily living deprivation indices, where we would expect that poor health would be the most important. Hence, selfrated health is measured as an integer variable. The BHPS questions on ADL limitations began with: 'Does your health in any way limit your daily activities compared to most people of your age? If respondents answered 'yes' to this question, they were asked which of four activities they would normally find difficult to manage on their own: doing housework; climbing stairs; dressing; and walking for Io minutes. A variable was created for the number of specified ADL limitations reported.

The respondents were also asked, 'Do you have any health problems or disabilities listed on this card?' and were presented with a list of $\mathrm{I} 3$ health problems/disabilities. Two such problems were 'difficulties seeing' and 'difficulties hearing'. Multiple sensory problems give rise to particular challenges in everyday life so we included three dichotomised (yes/no) variables for hearing difficulties, sight difficulties and difficulties with both 
hearing and seeing. Of the remaining Io health problems, only those which displayed a statistically significant association with any of the deprivation indicators when not controlling for other health variables were included. These were problems with: 'arms, legs, hands, back, or neck'; 'chest/ breathing problems, asthma, bronchitis'; and 'heart/blood pressure or blood circulation problems'. Problems with 'skin conditions/allergies', 'stomach/digestion', 'diabetes', 'alcohol/drugs', 'epilepsy', 'migraine' and 'other health problems' were excluded. Wave 9 (I999) of the BHPS did not include the questions on self-rated health or ADL limitations so the number of waves contributing to the analysis is reduced by one when health variables are examined.

The measure of housing tenure distinguished: owner-occupiers who had paid off their mortgage, owner-occupiers who still had a mortgage, and all other housing tenures. Housing costs were measured by gross monthly mortgage payments or rent. ${ }^{6}$ All the independent variables described above were time varying; that is, the values were those that applied at each wave of the BHPS.

\section{Statistical analysis}

Deprivation level was regressed on the independent variables described above or on a sub-set. The BHPS data were analysed in three ways: as a pooled cross-section data set; as panel data using a technique to allow for 'fixed effects'; and as panel data allowing for 'random effects'. In the first case, all selected years of BHPS data were pooled as if they were separate cross-sections, and ordinary least-squares regression carried out. This makes no use of the time element in the BHPS but provides results analogous to cross-sectional analyses and served as a basis for comparison with the longitudinal findings. The fixed effects and random effects approaches each exploit the fact that the BHPS observes changes in respondents' circumstances between the waves, as well as differences between respondents. In both the fixed effects and random effects approaches, it is assumed that there are individual-specific effects that are not captured by the independent variables which, under certain assumptions, longitudinal data can identify ( $c f$. Wooldridge 2002). In the fixed-effects model, these individual effects are assumed to be constant over time, whereas the random-effects model allows for individual effects to vary through time. Both the fixed-effects and random-effects models allow us to estimate the effects of an individual ageing, as distinct from the effect of being a particular age at a particular time. The random-effects model is designed to provide an estimate of the birth-cohort effect, but it can do this accurately only if there is no correlation between any unobserved characteristics that affect an 
T A B L E I. Combined deprivation score by individual and household characteristics: three analytical models compared

Analysis model

\begin{tabular}{|c|c|c|c|}
\hline \multirow[b]{2}{*}{ Characteristic } & & & \\
\hline & Pooled cross-section & Fixed effects & Random effects \\
\hline & \multicolumn{3}{|c|}{ Regression coefficients } \\
\hline Log income & $-0.57^{* * *}$ & $-0.15^{* * *}$ & $-0.25^{* * *}$ \\
\hline Number of children in household & $0.12 *$ & 0.00 & $0.07^{*}$ \\
\hline Has a partner $(\mathrm{I}=$ yes, $\mathrm{o}=\mathrm{no})$ & $-0.25^{* * *}$ & -0.03 & $-0.27^{* * *}$ \\
\hline Has retired $(\mathrm{I}=$ yes, $\mathrm{o}=\mathrm{no})$ & $-0.14^{* * *}$ & -0.00 & -0.03 \\
\hline Age $([$ age -50$] /$ io years $)$ & -0.03 & $0.22^{* * *}$ & $0.09^{* * *}$ \\
\hline Year-of-birth/Io & n.a. & n.a. & $0.12 * * *$ \\
\hline Constant & $3 \cdot 39$ & 0.53 & I. $3 \mathrm{I}$ \\
\hline$R^{2} / R h o$ & $(0.28)$ & $(0.75)$ & (o.69) \\
\hline
\end{tabular}

Note: n.a. not applicable.

Significance levels: $* p<0.05, * * * p<0.001$, using two-tailed tests.

individual's level of deprivation and those which are observed and included in the model. Statistically significant differences between coefficients on independent variables common to the fixed-effects and random-effects models would indicate that this assumption does not hold. ${ }^{7}$

\section{Results}

Table I presents the results of the regressions of the combined deprivation index using the three different statistical models. The combined deprivation index is regressed against income, age and, for the random-effects model, year-of-birth, controlling for household composition and retirement. In the pooled cross-sectional model, the age coefficient is not statistically significant $(p>0.05)$ implying that there was no cross-sectional variation in deprivation by age once income, household composition and retirement were taken into account. In the fixed-effects and random-effects models, the coefficients on age were positive and had high statistical significance $(p<$ o.ooI). They suggest that after controlling for income and these other variables, as individuals age, they become more deprived. The randomeffects model also suggests that year-of-birth was correlated with deprivation $(p<$ o.ooI $)$ : individuals born more recently have higher levels of deprivation at a given age and income level than those born earlier. There was, however, a sizeable difference in the coefficient on age in the fixed-effects and random-effects models (o.22 compared with o.o9; $p<$ o.oor), indicating that the assumptions underpinning the randomeffects model do not hold and we cannot rely on the estimated coefficient for year-of-birth. Nonetheless, while no significant cross-sectional 
T A B L E 2. Effects of ageing and cohort using three analytical approaches: five deprivation indicators, controlling for household income, household composition and retirement

\begin{tabular}{|c|c|c|c|c|c|}
\hline \multirow[b]{2}{*}{$\begin{array}{l}\text { Model } \\
\text { and effect }\end{array}$} & \multicolumn{5}{|c|}{ Deprivation indicator } \\
\hline & $\begin{array}{l}\text { Daily living: } \\
\text { don't have/do }\end{array}$ & $\begin{array}{l}\text { Daily living: } \\
\text { can't afford }\end{array}$ & $\begin{array}{c}\text { Consumer } \\
\text { durables }\end{array}$ & $\begin{array}{l}\text { Financial } \\
\text { strain }\end{array}$ & $\begin{array}{l}\text { Combined } \\
\text { score }\end{array}$ \\
\hline & \multicolumn{5}{|c|}{ Regression coefficients } \\
\hline $\begin{array}{l}\text { Pooled cross } \\
\text { Age }^{1}\end{array}$ & $\begin{array}{l}\text { ctions: } \\
\quad 0.06^{* *}\end{array}$ & $-0 . \mathrm{II}^{* * *}$ & $0.3^{6 * * *}$ & $-0.2 \mathrm{I}^{* * *}$ & 0.03 \\
\hline $\begin{array}{l}\text { Fixed effects } \\
\text { Ageing }^{1}\end{array}$ & $\begin{array}{l}\text { dels: } \\
0.3^{* * * *}\end{array}$ & $0.08^{*}$ & $0.4 \mathrm{I}^{* * *}$ & $-0.13^{* * *}$ & $0.22^{* * *}$ \\
\hline $\begin{array}{l}\text { Random-effe } \\
\text { Ageing }^{1} \\
\text { Year of birth }\end{array}$ & $\begin{array}{l}\text { models: } \\
\begin{array}{r}0.28 * * * \\
0.19 * * *\end{array}\end{array}$ & $\begin{array}{l}0.05 \\
0.12^{* * * *}\end{array}$ & $\begin{aligned} & 0.39^{* * * *} \\
- & 0.04^{*}\end{aligned}$ & $\begin{array}{r}-0.14^{* * * *} \\
0.08^{* *}\end{array}$ & $\begin{array}{l}\text { o.I9*** } \\
\text { o.I } 2^{* * * *}\end{array}$ \\
\hline
\end{tabular}

Note: I. Age and birth year coefficients indicate a Io year increase in age and birth year respectively. Significance levels: $* p<0.05, * * p<0.01, * * * p<0.001$, using two tailed tests.

association was observed between deprivation and age, the longitudinal association (or individual ageing effect) was significant in both longitudinal models. This suggests that the individual ageing effect is cancelled out by an opposite effect of year-of-birth to produce the small and insignificant cross-sectional association.

The cross-sectional analysis indicates that, controlling for age, income and household composition, retired people are less deprived than people who have not yet retired $(p<$ o.oor $)$. But the longitudinal analysis did not find a significant effect from the move into retirement. Similar results were found for household composition. People who lived with dependent children experienced greater deprivation than those who did not. Changes in the number of children in the household did not affect deprivation significantly in the fixed-effects model, but they did in the random-effects model. People living with a partner were less deprived than those living alone. ${ }^{8}$ The fixed-effects model implies that changes in partnership status did not affect deprivation beyond any associated income changes, but the random-effects model suggests there was an effect from changes in partnership status.

Table 2 compares the regression estimates for the four separate deprivation indices and the combined index. The table reports for the three statistical models, the estimated coefficients for age, and for the random-effects model for year-of-birth. To draw attention to the different interpretation of the coefficients on age for the cross-sectional and longitudinal analysis, we refer to 'age' in the cross-sectional model, and refer to 'ageing' in the longitudinal models. The models also control for income, household composition and retirement (as in Table I), though the 
coefficients on these additional controls are not shown. Among the cross-sectional estimates, the age coefficients were statistically significant $(p<0.05$ or $p<0.00 \mathrm{r})$ for all the four separate indices but their signs differed. Older people experienced more deprivation than younger people when deprivation is measured as daily living ('don't have'/'do') and possession of consumer durables. They experience less deprivation on the basis of not being able to afford daily living items/activities and in terms of financial strain. In the combined index, these effects appear to cancel out. The fixed-effects and random-effects models both suggest that ageing increases deprivation except in the case of financial strain, which falls as people age. These effects are clearly significant $(p<$ o.oor $)$ except in the case of the 'can't afford' version of the daily living index, where age was significant at the five per cent level in the fixed-effects model but not significant in the random-effects model. For the 'don't have/do' version of the daily living index, the coefficients on ageing in the longitudinal models were substantially larger than the coefficient on age in the cross-sectional model (0.32 in the fixed-effects model, 0.28 in the random-effects model, and 0.06 in the cross-sectional model). Year-of-birth was statistically significant in the random-effects model for all deprivation indices. A later or more recent birth year increased deprivation on all measures except for the consumer durable index. Individuals from later birth years were more likely to own consumer durables than those born earlier, controlling for age, income, household composition and retirement.

Tables 3 and 4 show the effects of also controlling for health or housing tenure and costs. To help the reader focus on the main comparisons, the presented results are confined to those from the fixed-effects model, and for ease of comparison, the regression estimates controlling only for household composition and retirement, as in the previous tables, are shown in the upper sections of Tables 3 and 4 . Introducing health into the combined deprivation score model had very little effect. None of the health measures was statistically significant. As before, only age and income were statistically significant and the sizes of their coefficients were hardly affected. A similar result was found for the four separate indices, although some of the health variables reached statistical significance (generally $p<0.05$ ). An exception, however, was financial strain. Poor general health status increased financial strain $(p<0.00 \mathrm{I})$, as did chest/breathing problems $(p<0.0 \mathrm{I})$ and heart/ circulatory problems $(p<0.05)$. Only for the financial strain index did the health variables taken together have a statistically significant effect. Introducing housing tenure and housing costs did not substantially change the relationships between deprivation, age and income (Table 4). Housing costs were not statistically significant in any model, and housing tenure was only statistically significant for the consumer durables index $(p<$ o.oI $)$. 
T A в L E 3. Effects of ageing, controlling for household income, household composition, and retirement, with and without control for poor health and impairment: fixed-effects models

\begin{tabular}{|c|c|c|c|c|c|}
\hline \multirow[b]{2}{*}{ Model and controls } & \multicolumn{5}{|c|}{ Deprivation indicator } \\
\hline & $\begin{array}{l}\text { Daily } \\
\text { living: don't } \\
\text { have/do }\end{array}$ & $\begin{array}{c}\text { Daily } \\
\text { living: } \\
\text { can't afford }\end{array}$ & $\begin{array}{l}\text { Consumer } \\
\text { durables }\end{array}$ & $\begin{array}{l}\text { Financial } \\
\text { strain }\end{array}$ & $\begin{array}{l}\text { Combined } \\
\text { score }\end{array}$ \\
\hline & \multicolumn{5}{|c|}{ Regression coefficients } \\
\hline \multicolumn{6}{|c|}{ No control for health/impairments: } \\
\hline Log income & -0.02 & $-0.09^{* * *}$ & $-0.08^{* * * *}$ & $-0.23^{* * *}$ & $-0.16^{* * *}$ \\
\hline No. of children in household & 0.05 & $-\mathrm{O} . \mathrm{OI}$ & $-\mathrm{O} . \mathrm{II}^{* *}$ & 0.02 & -0.02 \\
\hline Has a partner $(\mathrm{I}=$ yes, $\mathrm{o}=\mathrm{no})$ & -0.07 & $0.12^{*}$ & $-0.19^{* * *}$ & 0.09 & -0.01 \\
\hline Has retired $(\mathrm{I}=$ yes, $\mathrm{o}=\mathrm{no})$ & $-0.07^{*}$ & -0.02 & 0.03 & $0.09^{* *}$ & O.OI \\
\hline Ageing $^{\mathbf{1}}$ & $0.32^{* * *}$ & $0.08 *$ & $0.40^{* * *}$ & $-0.15^{* * *}$ & $0.22 * * *$ \\
\hline Constant & -0.27 & 0.24 & $0.33^{* *}$ & $\mathrm{I} .25 * * *$ & $0.63^{* * * *}$ \\
\hline \multicolumn{6}{|c|}{ Controlling for health/impairments: } \\
\hline Log income & -0.02 & $-0.09^{* * *}$ & $-0.08^{* * *}$ & $-0.23^{* * *}$ & $-0.16^{* * *}$ \\
\hline No. of children in household & 0.05 & $-\mathrm{O} . \mathrm{OI}$ & $-0.1 I^{* *}$ & 0.03 & -0.02 \\
\hline Has a partner $(\mathrm{I}=$ yes, $\mathrm{o}=\mathrm{no})$ & -0.07 & $0.12^{*}$ & $-0.19^{* * *}$ & 0.09 & -0.01 \\
\hline Has retired $(\mathrm{I}=$ yes, $\mathrm{o}=\mathrm{no})$ & $-0.07^{*}$ & -0.02 & 0.03 & $0.09^{* * *}$ & O.OI \\
\hline Ageing $^{1}$ & $0.30^{* * *}$ & 0.06 & $0.4 \mathrm{I}^{* * * *}$ & $-0.19^{* * *}$ & o.19*** \\
\hline Health status $(I-5)$ & 0.00 & 0.00 & 0.00 & $0.06 * * *$ & O.OI \\
\hline Has sight difficulties ${ }^{2}$ & o.OI & -0.03 & O.OI & -0.02 & $-\mathrm{o.OI}$ \\
\hline Has hearing difficulties ${ }^{2}$ & 0.00 & $0.05^{*}$ & 0.00 & - O.OI & O.OI \\
\hline Sight and hearing difficulties ${ }^{2}$ & $0.15^{*}$ & 0.05 & $-\mathrm{O} . \mathrm{OI}$ & -0.06 & 0.08 \\
\hline Anxiety etc. $(\mathrm{O}-\mathrm{I})$ & 0.06 & 0.02 & 0.02 & 0.03 & 0.04 \\
\hline Arms/legs/hands ${ }^{2}$ & 0.02 & $0.04^{*}$ & $-\mathrm{O} . \mathrm{OI}$ & 0.02 & 0.02 \\
\hline Chest/breathing $^{2}$ & 0.00 & 0.02 & $-0.04^{*}$ & $0.10^{* *}$ & 0.03 \\
\hline Heart/circulation ${ }^{2}$ & O.OI & 0.02 & $-0.03^{*}$ & $0.05^{*}$ & O.OI \\
\hline ADL limitation $(\mathrm{I}=$ yes, $\mathrm{o}=\mathrm{no})$ & -0.01 & -0.02 & 0.00 & 0.03 & 0.02 \\
\hline No. of ADL limitations $(0-4)$ & 0.02 & O.OI & 0.00 & 0.00 & O.OI \\
\hline Constant & -0.26 & 0.23 & 0.33 & I.I I $* * *$ & $0.60 * * *$ \\
\hline $\begin{array}{l}\text { Test }^{3} \text { of all health indicators } \\
\text { combined } p \text { (I } \text { d.f.) }>\end{array}$ & $0.20 \mathrm{I}$ & 0.248 & 0.267 & 0.000 & 0.IO2 \\
\hline
\end{tabular}

Notes: $\mathrm{I}$. The age coefficient indicates a Io year increase in age. $2 . \mathrm{I}=$ yes, $\mathrm{o}=$ no. 3 . The last line shows the probability that the observed relationships with all the health indicators combined arose by chance: a small $p$ indicates a low probability and therefore a significant relationship.

Significance levels: $* p<0.05, * * p<0.01, * * * p<0.001$ using two tailed tests.

Becoming an owner-occupier reduced consumer durable deprivation, while including housing costs and tenure had negligible effects on the coefficients of the other included variables.

\section{Discussion}

A starting point for the analysis presented in this paper was the finding from previous cross-sectional studies that older people experience less deprivation given their income than younger people. By exploiting longitudinal

\section{CAMBRIDGE JOURNALS}


T A B L E 4. Effects of ageing, controlling for household income (before housing costs), household composition, and retirement with and without control for housing costs and tenure: fixed-effects models

Deprivation indicator

Model and variable

Daily living: Daily living: Consumer Financial Combined don't have/do can't afford durables strain score

No control for housing costs

Log income before housing costs

No. of children in household

Has a partner $(\mathrm{I}=$ yes, $\mathrm{o}=\mathrm{no})$

Has retired $(\mathrm{I}=$ yes, $\mathrm{o}=\mathrm{no})$

Ageing ${ }^{1}$

Constant
Regression coefficients

$\begin{array}{ccccc}-0.01 & -0.09^{* * *} & -0.1 I^{* * *} & -0.28^{* * *} & -0.18 * * * \\ 0.06 & 0.01 & -0.10^{* *} & 0.04 & 0.00 \\ -0.06 & 0.12^{*} & -0.19^{* * *} & 0.06 & -0.02 \\ -0.07^{* *} & -0.02 & 0.0 \mathrm{I} & 0.08^{* *} & -0.0 \mathrm{I} \\ 0.32^{* * *} & 0.08^{*} & 0.40^{* * *} & -0.15^{* * *} & 0.22^{* * *} \\ -0.34^{*} & 0.24 & 0.49^{* * *} & \mathrm{I} .56^{* * *} & 0.74^{* * *}\end{array}$

\section{Controlling for housing costs and tenure status}

Log income, before housing costs

No. of children in household

Has a partner $(\mathrm{I}=$ yes, $\mathrm{O}=\mathrm{no})$

Has retired $(\mathrm{I}=$ yes, $\mathrm{O}=\mathrm{no})$

Ageing ${ }^{1}$

Log housing costs

Outright owner $(\mathrm{I}=$ yes, $\mathrm{o}=\mathrm{no})$

Paying mortgage $(\mathrm{I}=$ yes, $\mathrm{O}=$ no)

Constant

$-0.09^{* * *}$
0.01
0.11
-0.02
$0.08^{*}$
0.03
0.17
0.11
0.08

$\begin{array}{ccc}-0 . \mathrm{II} * * * & -0.28^{* * *} & -0.18^{* * *} \\ -0 . \mathrm{II} \mathrm{I}^{* *} & 0.04 & 0.00 \\ -0 . \mathrm{I} 8^{* * *} & 0.06 & -0.02 \\ 0.0 \mathrm{I} & 0.08^{*} & -0.0 \mathrm{I} \\ 0.42^{* * *} & -0.14^{* * *} & 0.23^{* * *} \\ -0.0 \mathrm{I} & -0.0 \mathrm{I} & 0.00 \\ -0.30^{* *} & -0.13 & -0.10 \\ -0.2 \mathrm{I}^{* *} & -0.03 & -0.05 \\ 0.7 \mathrm{I}^{* * *} & \mathrm{I} .65^{* * *} & 0.79^{* * *}\end{array}$

Note: I. The age coefficient indicates a ro year increase in age.

Significance levels: $* p<0.05, * * p<0.01, * * * p<0.001$ using two tailed tests.

data from the British Household Panel Survey, we set out to test whether this cross-sectional finding meant that, as people age, they achieve higher (relative) living standards for a given income. In the cross-sectional analysis, different results were obtained for the different deprivation indices (our indicators of living standards), but for the combined index, age was not statistically significant. The longitudinal results also differed according to the deprivation index, but indicated overall that deprivation increases as individuals age, controlling for income and other relevant factors. Ageing had a beneficial effect only on financial strain among the deprivation measures. The analysis of the influence of health and housing costs on the level of deprivation indicated that they did not explain away the effects of age. The results therefore suggest that it would be dangerous to base policy on an assumption that as people age they need less income to maintain their living standards - if anything, the opposite is likely to be true.

Using an index of deprivation based on possessed items and pursued activities revealed that the role of age depends on whether items not possessed and activities not pursued were not wanted or not affordable. The cross-sectional results implied that older people have higher levels of 
deprivation than younger people when this distinction is ignored, but if deprivation is defined as not being able to afford desired items/activities rather than just their absence, then deprivation levels are lower among older people. In the longitudinal models, the ageing effect on the can't afford index was smaller and statistically uncertain. This is an important finding given the debate about the validity of the can't afford measure (McKay 2004).

It is interesting that both deprivation indices that produced a weak or negative ageing effect involved subjective responses. The financial strain index is inherently subjective, as is the distinction between not wanting and not affordable. It is possible that this finding says more about how ageing affects people's perception of their budgeting process than about its effect on deprivation. The finding is also consistent with the 'adaption' hypothesis found in the literature on the economics of happiness (Clark, Fritjers and Shields 2008). It has been suggested that people's adaptation to increased income partly explains why rising incomes do not produce sustained improvements in subjective wellbeing. Extrapolating this idea to older people, their adaptation to a lower income may explain the weak or negative ageing effect on the subjective deprivation measures.

The cohort effects that are implied by the random-effects model for some of the deprivation indices suggest that more-recently-born pensioners are more deprived at a given age and income than those born longer ago. This indicates that, other things being equal, each successive generation of retired people needs higher pension levels than its predecessors. But other things are not equal, and the ageing effects generally suggest the opposite. The combination of these two effects could be taken to support a policy in which pensions and other benefits for older people do not change with age. Previous cross-sectional evidence has suggested that deprivation levels decrease with age. Our longitudinal analysis suggests, however, that there is insufficient evidence to justify reducing benefits with increasing age, or indeed for anyone to plan on the assumption that as they get older they will need less income to avoid deprivation.

We have considered three characteristics known to correlate with old age that might appear to be related to deprivation but which are not a direct function of age. These include being retired (most people retire between the ages of 55 and 70 years); housing tenure (earlier cohorts have low rates of owner-occupation, but most owner occupiers have paid off their mortgage by the time they retire); and ill-health or disability (prevalence and severity rates rise progressively with increasing age). Our conclusions about ageing and cohort effects remain, after taking account these potentially confounding influences. Since other sources have demonstrated a strong relationship between disability and deprivation 
(e.g. Zaidi and Burchardt 2005), further investigation of the three-way link between age, disability and deprivation is worth pursuing.

The overall conclusions are surprising. The starting point for the research was the observation that deprivation rates tend to decline with age among older people (controlling for income). We wanted to know whether this cross-sectional trend could be explained by either a cohort effect (people born long ago are less deprived at a given income), or by a 'beneficial' ageing effect, namely that people's ability to convert income into standard of living improves as they age. It turns out that, as hypothesised, there is probably a cohort effect, but it is unexpectedly offset by a 'detrimental' or opposite ageing effect, people's ability to convert income into their standard of living deteriorates as they age.

The research reported has used British data, but we are not aware of any policies or other characteristics specific to Britain that would directly explain the contrasting ageing and cohort effects, so it is possible that the same patterns apply in other countries. Existing European Community Household Panel data could be used to replicate the analysis in western Europe; and the forthcoming panel data from the EU Statistics on Income and Living Conditions will provide an opportunity to extend it to the enlarged Union (see http://qb.soc.surrey.ac.uk/surveys/eusilc/eusilcintro.html).

\section{Acknowledgements}

This paper arose from research financed by the United Kingdom Department for Work and Pensions (DWP). Thanks are due to Alasdair Crockett, Nicola Dominy, Naomi Finch, Peter Kemp, Elaine Kempson, Steve McKay, Cheti Nicoletti and Steve Pudney for comments and advice during the course of the work. The analysis, interpretation and conclusions are the responsibility of the authors and do not reflect the views of the DWP or the individuals named in this acknowledgement.

\section{NOTES}

I The PSE authors used the term consensual 'poverty' rather than 'deprivation'. Since the relationship between the concepts of poverty and deprivation is itself a matter of debate ( $c f$. Berthoud, Blekesaune and Hancock 2006) we use the term deprivation in this context as we are referring to a consensually defined index of deprivation.

2 Such cohort effects could also be viewed as period effects since different cohorts have lived through different periods of history. It is well established that it is not possible to separate more than two of age, cohort and period effects.

3 The questions comprising the index of financial strain were asked of all adults in the household, and were highly correlated within households.

4 The BHPS list of items is shorter than those used in the PSE and the Family Resources Survey. McKay and Collard (2004) reported that a short list of items provides an adequate proxy for a longer list. More generally, any well-constructed list of 
deprivation items should provide the same broad analytical results as any other, if the deprivation indicator approach has any validity.

5 The reference to 'people of your own age' might be expected to weaken the relationship between health and age, but comparisons with results from the Health Survey for England, which asked similar questions without referring to 'people of your own age', suggested there was no major effect of the difference in question wording (Berthoud, Blekesaune and Hancock 2006: Appendix D).

6 In the case of renters who receive the (Social Security) Housing Benefit, rent is gross of any Housing Benefit. Differences in renters' and owner-occupiers' net housing costs (i.e. after deducting Housing Benefit) tend to be smaller than differences between gross costs because there is no equivalent of housing benefit for owner-occupiers. Differences in gross housing costs are also exaggerated by the exclusion of repairs and maintenance costs for owner-occupiers. Such costs tend to be included in rent paid by renters but are not recorded in the BHPS for owner-occupiers.

7 The statistical analysis was carried out using the STATA software package (see http:// www.stata.com/).

8 This finding suggests that couples have a higher standard of living than single people, on a given income. It contradicts the assumptions in equivalence scales, but is consistent with other analyses of deprivation (Berthoud and Ford I996; Berthoud, Bryan and Bardasi 2004).

\section{References}

Atkinson, A., Cantillon, B., Marlier, E. and Nolan, B. 2002. Social Indicators: The EU and Social Exclusion. Oxford University Press, Oxford.

Banks, J., Blundell, R. and Tanner, S. I998. Is there a retirement-savings puzzle? American Economic Review, 88, 4, 769-88.

Berthoud, R. and Ford, R. I996. Relative Needs: Variations in Living Standards of Different Types of Household. Policy Studies Institute, London.

Berthoud, R., Bryan, M. and Bardasi, E. 2004. The Dynamics of Deprivation: The Relationship between Income and Material Deprivation over Time. Research Report 219, Department for Work and Pensions, Corporate Document Services, Leeds, West Yorkshire, UK.

Berthoud, R., Blekesaune, M. and Hancock, R. 2006. Are 'Poor' Pensioners 'Deprived'? Research Report 364, Department for Work and Pensions, Corporate Document Services, Leeds, West Yorkshire, UK.

Clark, A., Fritjers, P. and Shields, M. 2008. Relative income, happiness, and utility: an exploration of the Easterlin paradox and other puzzles. Fournal of Economic Literature, 46, I, 95-I44.

Department for Work and Pensions (DWP) 2008. Households Below Average Income 1994/95 to 2006/7. DWP, London. Available online at http://www.dwp.gov.uk/asd/hbai/ hbai2007/contents.asp [Accessed I8 July 2008].

Finch, N. and Kemp, P. 20o6. Which Pensioners Don't Spend Their Income and Why? Research Report 384, Department for Work and Pensions, Corporate Document Services, Leeds, West Yorkshire, UK.

Gordon, D., Adelman, L., Ashworth, K., Bradshaw, J., Levitas, R., Middleton, S., Pantazis, C., Patsios, D., Payne, S., Townsend, P. and Williams, J. 20oo. Poverty and Social Exclusion in Britain. Joseph Rowntree Foundation, York.

Guio, A.-C. 2005. Material deprivation in the EU. Statistics in Focus, $2 \mathbf{I}$ (Eurostat, Luxembourg).

Halleröd, B. 1995. The truly poor: direct and indirect consensual measurement of poverty in Sweden. Fournal of European Social Policy, 5, 2, II I-29. 
LaRochelle-Côté, S., Myles, J and Picot, G. 2008. Income Security and Stability During Retirement in Canada. Research Paper irFoorgM, Statistics Canada, Ottawa.

Mack, J. M. and Lansley, S. I985. Poor Britain. Allen and Unwin, London.

Mayer, S. and Jencks, C. I989. Poverty and the distribution of material hardship'. Fournal of Human Resources, 24, I, 88-II3.

McKay, S. 2004. Poverty or preference: what do 'consensual deprivation indicators' really measure? Fiscal Studies, 25, 2, 201-23.

McKay, S. and Collard, S. 2004. Developing Deprivation Questions for the Family Resources Survey. Working Paper i3, Department for Work and Pensions, London.

Miniaci, R., Monfordini, G., Weber, G. 2003. Is There a Retirement-consumption Puzzle in Italy? Working Paper WPo3/I4, Institute for Fiscal Studies, London.

Pantazis, C., Gordon, D. and Levitas, R. (eds) 2006. Poverty and Social Exclusion in Britain: The Millennium Survey. Policy Press, Bristol, UK.

Patsios, D. 200o. Poverty and Social Exclusion among the Elderly. Poverty and Social Exclusion Working Paper 20, Townsend Centre for International Poverty Research, University of Bristol, Bristol, UK.

Pensions Policy Institute 2004. State Pension Reform: The Consultation Process. Pensions Policy Institute, London.

Portrait, F., Deeg, D. and Alessi, R. 2004. Examining the Dutch Disability Trends in the Nineteennineties: Age, Period and Cohort Effects. Discussion Paper 04-20, Tjalling C. Koopmans Research Institute, University of Utrecht, Utrecht, The Netherlands. Available on-line at http:/www.koopmansinstitute.uu.nl [Accessed 20 November 2008].

Prus, S. G. 2002. Changes in income within a cohort over the later life course: evidence for income status convergence. Canadian Fournal of Ageing, 2 I, 4, 495-504.

Romeri, E., Baker, A., and Griffiths, C. 2006. Mortality by deprivation and cause of death in England and Wales 1999-2003. Health Statistics Quarterly, 32, Winter, 19-34.

Smith, S. 2006. The retirement-consumption puzzle and involuntary early retirement: evidence from the British Household Panel Survey. Economic Fournal, r r6, 510, I30-48.

Taylor, M. (ed.) with Brice, J., Buck, N. and Prentice-Lane, E. 20o6. British Household Panel User Manual. University of Essex, Colchester, Essex, UK.

Townsend, P. 1979. Poverty in the United Kingdom. Penguin, Harmondsworth, UK.

Whelan, C. T., Layte, R., Maitre, B. and Nolan, N. 200I. Income, deprivation and economic strain: an analysis of the European Community Household Panel. European Sociological Review, I 7, 4, 357-72.

Williamson, J. M. and Smeeding, T. M. 2004. Sliding into Poverty? Cross-National Patterns of Income Source Change and Income Decay in Old Age. Centre for Retirement Research, Boston College, Boston, Massachusetts.

Wooldridge, J. M. 2002. Econometric Analysis of Cross Section and Panel Data. MIT Press, Cambridge, Massachusetts.

Zaidi, A. and Burchardt, T. 2005. Comparing incomes when needs differ: equivalization for the extra costs of disability. Review of Income and Wealth, 5I, I, 89-II4.

Zigante, V. 2008. Ever rising expectations: the determinants of subjective welfare in Croatia. Financial Theory and Practice, 32, 2, II 5 -37.

Address for correspondence:

Accepted 2 I November 2008; first published online I April 2009

Ruth Hancock, School of Medicine, Health Policy and Practice, University of East Anglia Norwich, Norfolk NR4 7 TJ, UK.

E-mail: R.Hancock@uea.ac.uk 